\title{
A Positivist Tradition in Early Demand Theory
}

\author{
David Teira
}

Dpt. of Logic, History and Philosophy of Science (UNED) and Urrutia Elejalde Foundation

Mailing Address:

Dpto. de Lógica, Historia y Filosofía de la ciencia UNED | Humanidades

Paseo de Senda del Rey 7

28040 Madrid

Spain

dteira@fsof.uned.es

Phone: 34913507605 


\title{
A Positivist Tradition in Early Demand Theory
}

\begin{abstract}
:
In this paper I explore a positivist methodological tradition in early demand theory, as exemplified by several common traits that I draw from the works of V. Pareto, H. L. Moore and H. Schultz. Assuming a current approach to explanation in the social sciences, I will discuss the building of their various explanans, showing that the three authors agreed on two distinctive methodological features: the exclusion of any causal commitment to psychology when explaining individual choice and the mandate to test the truth of demand theory on aggregate data by statistical means. However, I also contend, from an epistemological point of view, that the truth of demand theory was conceived of in three different ways by our authors. Inspired by Poincaré, Pareto assumed that many different theories could account for the same data on individual choice, coming close to a kind of conventionalism -though I prefer to refer to this position as theoreticism. Moore was himself akin to Pearson's approach, which could be named descriptivist insofar as it resolved scientific laws into statistical descriptions of the data. Finally, Schultz tried to reconcile both approaches in an adequationist stance with no success, as we shall see.
\end{abstract}

KEYWORDS: positivism, Pareto, Moore, Schultz, demand theory, methodology

\section{BIO}

David Teira is assistant professor in the Dpt. of Logic, History and Philosophy of Science (UNED) and research associate of the Urrutia Elejalde Foundation. His Ph.D. thesis Azar, economía y politica en Milton Friedman won the best dissertation award of the Spanish Society for Logic and Philosophy of Science for the period 2001-2003. 


\section{A Positivist Tradition in Early Demand Theory}

David Teira Serrano

\section{BEFORE POSITIVISM}

Could economics be a positive science? A lesson to learn from the methodological debate of the $20^{\text {th }}$ century is that the answer to this question depends very much on what we take positivism to be. A vast majority of methodologists (and practitioner economists as well) have adhered to a view received from mainstream philosophy of science, in which positivism was most often equated to logical positivism. More recently, however, it has been suggested that a different positivist tradition may be found in economics, underlying certain developments in demand theory in the $1920 \mathrm{~s}^{\mathrm{ii}}$. In this paper, I will try to elaborate on this suggestion, which I will pursue through a collection of texts not usually related to positivism. My overall purpose is to infer therefrom a definition of positivist methodology as exercised by early demand theorists, whilst shedding some light on the epistemological challenges they had to face.

A consensual point in most textbooks on the philosophy of the social sciences (at least in the analytic tradition: e.g., Rosenberg 1995) is that a proper explanation of a social event should consist of an intentional account of the decision of the individual agent and an analysis of the aggregate effects that result from adding such decisions. Demand theory might be considered canonical in this respect for providing both explanatory ingredients, utility theory articulating the former and partial or general equilibrium the latter. However, this methodological consensus allows for a variety of positions when it comes to the empirical testing of the explanations so construed. That is, to the assesment of the truth of the underlying theories. In this paper, I will defend the existence of two common 
methodological and epistemological features that appear in the explanations of demand provided by three leading economists of the first part of the $20^{\text {th }}$ century (V. Pareto, H. L. Moore and H. Schultz) and define a common position that I take to be distinctively positivist.

The first feature was to dispense with unobservable psychological variables at the micro level driven by the commitment of attaining plainly empirical explanations of individual choices in demand analyses. The status of utility theory was therefore questioned and several methodological decisions were then due ranging from an ordinalist reform (Pareto and Schultz) to its abandonment (Moore). On the epistemological side, the second distinctive feature of these three authors is their option for the assesment of the truth value of demand theory at the macro level, statistically testing the explanations of aggregate market data. Though experimentation at the micro level was sometimes entertained, our three economists were probably fascinated by the possibility of uncovering the laws of the market by means of the new statistical tools that became available at the turn of the century.

I describe this position as positivist on the basis of the methodological and epistemological proximity that might be appreciated between the positivist tradition in $19^{\text {th }}$ century physics and our economic trio. Namely, dispensing with the mechanistic analysis of the unobservable behaviour of individual atoms and analyse instead its aggregation by means of statistics. I will argue that this proximity is quite noticeable if some attention is paid to the influence received from Henri Poincaré and Karl Pearson by, respectively, Pareto and Moore. I refer to the common position of these two authors and Schultz as the source of a tradition as a hypothesis on the possibility of tracing their influence on later demand theorists, though this is a historical endeavour that I will not pursue in this paper - 
just as I will not explain the convergence of the positions of Pareto, Moore and Schultz as a result of their mutual relations (though obvious in the case of the las two). However, I hope that my case is informed enough as not to be unpalatable for the historian.

My main concern is philosophical: the methodological and philosophical dilemmas these three authors had to face in their analyses of demand (observability, underdetermination, ceteris paribus clauses, etc.) were objectively there. In particular, I will try to show how they took different positions in respect of truth, discussing whether an independent correspondence between theory and empirical data could be established (Schult'z initial descriptivist hope); if it was always theoretically loaded (Pareto's and Schultz's latter theoreticism); or if a full reduction of theoretical entities in the data was possible (Moore's descriptivism). All these are still coherent positions that must be addresed on their own merits. This will allow us to assess what progress was really made in respect of it by subsequent positivist methodologies, such as that of Friedman's.

I will proceed as follows. A brief discussion of Paretian choice theory, as exposed in his 1909 Manuel d'économie politique will serve as an introduction. I will present the two methodological and epistemological tenets that, in my view, define early positivism in demand theory, as they were occasionally entertained (but not developed) by Pareto and his own position in respect of truth. An in-depth discussion of Moore's early works up to 1914 comes next, where I show how he attempted to introduce Karl Pearson's statistical ideas into demand theory, departing from the neoclassical tradition in which he had been raised. That is key to understanding his most controversial result, a positively sloped demand curve, presented herein as a by-product of his methodological and epistemological assumptions. The final section deals with Henry Schultz's contribution to the 1920s debate 
on demand curves, understood as a failed compromise between Pareto and Moore's epistemological stances. A brief conclusion on the consequences of this failure for the subsequent development of positivism in demand theory follows.

\section{AN INTRODUCTORY REMARK ABOUT PARETO’S THEORETICISM}

Pareto is usually counted among the forerunners of a positivistic approach to demand theory, mainly because of his well-known ordinalist stance. According to certain methodologists, dispensing with psychological unobservable entities would constitute, a step forward for neoclassical economists in their quest for empirically grounded theories ${ }^{\mathrm{iii}}$. However, as Bruni and Guala 2001 recently pointed out, Pareto was closer to certain $19^{\text {th }}$ century epistemologies, namely Mill, than to modern behaviourism. According to their analysis, Pareto was rather a «practical cardinalist» who acknowledged that utility was probably cardinal in nature but, being a mere abstraction, the economist as scientist was not entitled to affirm its existence. The ordinalist approach was instead settled as a Millian concrete deductive method, whose principles, though void of psychological content, were «entirely deduced from facts». Having developed the latter during the years 1896 to 1899 , Pareto occasionally returned to the former, as he did in his 1909 Manuel: instead of excluding each other, both approaches were equally admissible for Pareto, even if the conclusions derived therefrom were not of equal cogency ${ }^{\text {iv }}$. I would like to cast some light on Pareto's positivism, separating it from his Millian theses. More precisely, I will focus on the deduction of theory from facts, in order to show how the two methodological tenets that will identify the positivist tradition in demand theory derive thereof. 
Let us recall several basic Paretian tenets. The demand theorist abstracted from the agent's behaviour a certain pattern of action, in which means and ends are logically connected. The theorist was to produce a mathematical idealization of this logic, by means of which he could approximate reality through formal correspondences (Pareto [1909] 1981: 11). Scientific truth is attained when the structure of a set of concepts is in complete accord with the relations underlying certain phenomenon (Pareto [1909] 1981: 43-44): i.e., this would be a clear adequationist position. While in line with his overall view of pure analytic science (Bruni and Guala 2001: 35-39), let me notice that at this particular point of the Manuel, Pareto seems to be arguing under the influence of Henri Poincaré's La science et l'hypothèse (Poincaré [1902] 1968).

A significant part of $19^{\text {th }}$ century positivism can be accounted for as a reaction against the mechanistic programme in physics $^{\mathrm{v}}$, and in this respect Poincaré should count among its trailblazers. Though his views on science evolved all over his career, La science et l'hypothèse contains a severe criticism of the architecture of mechanistic explanations: every theoretical entity in physics - atoms, for instance - is to be reinterpreted on the basis of sense data. Far from representing real causal links, as the mechanists claimed, the mathematical apparatus articulating those concepts in laws turns out to be an empirically fruitful convention, freely chosen by the theoretician. Therefore, the formal structure of every theory may be interpreted in many different ways inasmuch as it succeeds in expressing how the phenomena relate to each other ${ }^{\mathrm{vi}}$.

When arguing for the explanations of individual action based on utility theory, Pareto seems to be inspired by Poincaré's suggestion, which he explicitly quotes ${ }^{\mathrm{vii}}$. Just as the equations of celestial mechanics may be considered true even after renouncing universal 
gravitation, so utility theory is to be founded independently of any substantive interpretation whatsoever (Pareto [1909] 1981: 49). More precisely:

[I]n that case it is possible that, in order to make things a little more concise, some people might think it appropriate to give some name to the quantity $I$; thus in mechanics it was considered appropriate to give the name kinetic energy to a certain integral, and the name entropy to another in thermodynamics. Nevertheless, since there is so little to be gained by doing that, we could give no name at all to function 5 [the utility function $I=\psi(x, y, \ldots) ;$ DTS], and designate it simply by the letter $I$; nothing would be changed in the economic theories. ${ }^{\text {vii }}$

A first feature of the positivist methodology in demand theory is derived thereof ${ }^{\mathrm{ix}}$ : the explanation of individual action should be kept apart from psychology, avoiding the search for inner unobservable causes and focusing instead on the logic of observable behavioral routines. The road to experimental testing in economics was thus open (Pareto [1909] 1981: 174, 263-4; [1900] 1982: 377). Yet, Pareto raised a most challenging epistemological issue when he contended that many different theories may perform equally well to account for a given body of data, as Poincaré was already claiming (Pareto [1909] 1981: 44). What initially appeared to be an adequationist position grounded on a correspondence theory of truth was therefore converted into a conventionalist stance, as a result of an underdetermination problem. Pareto offered no rule in order to deal with theory selection and choose between different conventions.

Both the possibility of experimentation and the choice among different equally performing theories amount to no more than mere matters of principle, as Pareto never 
considered either going into the laboratory or assessing alternative choice theories. The reason for this lies in what I take to be the second distinctive feature of the positivist methodology in demand theory: the mandate to test it on aggregate data by means of statistics.

This is precisely so in political economy, for there we consider only average phenomena and those involving large numbers. We speak of the individual, not in order actually to investigate what one individual consumes or produces, but only to consider one of the elements of a collectivity and then add up the consumption and the production of a large number of individuals. ${ }^{\mathrm{x}}$

Statistical testing was an entirely natural move for a positivist in economics, as it had been in physics, since it departed from mechanistic explanations based on individual behaviour and used random variables to account for aggregate data (Barbut 1999: 106107). In fact, Pareto expected statistics to produce new «empirical laws» which could be somehow compared to the theoretical ones (Pareto [1907-8] 1982: 575). In spite of the relevance of his contributions to statistics, this was again a merely programmatic claim, since he never tested demand theory on the data. Therefore, he left unanswered a question that Moore and Schultz were to raise inmediately: did his conventionalist caveat also apply at the macro level? In other words, were the aggregate demand curves also underdetermined by the data? I will discuss now Moore's and Schultz's response to both questions. 


\section{HENRY LUDWELL MOORE’S STATISTICAL POSITIVISM}

Whereas Pareto may be considered an occasional positivist, who simply entertained certain methodological ideas at a particular stage in his career, Henry Ludwell Moore graduately became an accomplished one, dispensing with psychological explanations of individual economic choices and focusing instead on statistical tests on aggregate data. His quest for statistical tools to test economic theories took him to London to the laboratory of Karl Pearson, who belonged, like Poincaré, to the positivist tradition sprung from physics via Ernst Mach ${ }^{\mathrm{xi}}$. Under the impact of his views on causation and scientific laws, Moore strived to introduce them into economic theory in two stages, which I will discuss in this section. During the first, ranging from the completion of his doctoral dissertation in 1895 to 1911, Moore tried to test different static theories about wages on dynamic series of data, as Pareto advocated, although with a clear influence of certain suggestions by Marshall. It is precisely as a result of the dismissal of his tests by the latter that Moore turned himself into a full-fledged positivist and abandoned the neoclassical tradition. In my view, this positivist stance sets the proper framework for understanding Moore's most controversial result, the positively sloped demand curve he obtained in his 1914 Economic Cycles.

A few preliminary remarks on the significance of Pearson's positivism are in order, so that its influence on Moore can be properly assessed. Karl Pearson's opus magnum, the Grammar of Science, may be read as an statistical restatement of a number of ideas previously discussed by Ernst Mach in his Analysis of Sensations — which is probably the reason why he received the dedication to its sixth edition, in 1911. Among these, for our own purposes the most important one is causation. To put it very briefly, for Mach, the most basic reality we can access is complexes of sensations, upon which our world's 
«furniture» is built (Mach 1957: 36). Sciences should therefore account for those complexes whose association is more stable in space than in time, establishing their functional dependence on each other. In spite of all mechanistic claims, causation, in Machian terms, amounts to nothing more than a formal relation without any substantial ontological import, apart from sensations (Mach 1957: 87). Pearson's main contribution to the positivist tradition may be the mathematical specification of this functional dependence by means of statistics, which he introduced, in the second edition of his Grammar of Science. Causation could be precisely measured by the correlation coefficient as long as it was reduced, as Mach claimed, to an index of the degree of association between certain sequences of sense data arrayed in a contingency table. Against mechanism, Pearson refused to consider other form of causal necessity than the inferential cogency imposed by the correlation coefficient (Pearson 1900: 283-84; 1911: 310-11).

For Pearson it was not simply a matter of epistemological principle. Inspired by Galton and Weldon, he really dispensed with mechanistic explanation in his own biological research (Pearson 1900: 332). Statistics could solve the problem of causal analysis of natural selection, overcoming the debate on the causal mechanism of genetic inheritance (Pearson 1900: ch. 10): according to Pearson, the ancestral law of heredity was hailed as being the biological analogue of the universal law of gravitation. The biometrician would obtain a type for each organ of a plant or an animal, estimating its statistical concentration in a given population (Armatte 1995: 524). Hence, each individual organ can be analysed in terms of its deviation from the type (Pearson 1900: 384). Assuming a certain statistical distribution for a type, the biometrician would measure by means of correlation analysis the intergenerational variation of its parameters in order to analyse the effects of natural 
selection on an organ. According to Pearson, the bigger the concentration around the mean of each type, the more intensive the struggle for life. Correlating the measures of each particular organ in a progenitor and its offspring the biometrician would be able to assess its role in natural selection, no matter how it were inherited.

Struggle for life was a significant economic metaphor long before Henry Ludwell Moore started to work on the distribution of wages, the topic of his 1896 dissertation at Johns Hopkins, advised by John Bates Clark. Many American economists of the time were discussing how to account for the distribution of entrepreneurial profits and workers' salaries in a neoclassical setting. Moore's supervisor contributed to the debate with his The Distribution of Wealth, in which he successfully introduced a distinction between a static and a dynamic approach (Dewey 1987: 430) ${ }^{\mathrm{xii}}$. According to Clark, most classical (Clark 1899: vi) and neoclassical economists explained the distribution of wages statically, in a deductive fashion. His own analysis proceeded along this path, though he announced that the best research prospects lay ahead in the development of the dynamic approach, an inductive verification of the static results (Clark, 1905: 256).

After completing his dissertation, Moore devoted fifteen more years to the analysis of wages. It seems that Moore assumed the execution of Clark's project ${ }^{\text {xiii }}$, but, as we will see, it was Marshall who inspired a number of crucial steps to accomplishing it. This was done when Moore's Laws of Wages went to print in 1911, although a series of three papers published in 1907 had already anticipated its main results. Aiming at a statistical testing of the «pure» theories of wages (Moore 1907c: 61; 1907a: 638), Moore developed an inductive approach anchored in the Pearsonian concept of variability (Moore 1907c: 62). «Guided by the experience» of the biometricians (Moore 1907c: 63), Moore found in the 
standard deviation of wages an index of the social struggle for life. According to Moore, the variability of wages points to changes in the conditions under which workers compete with each other for jobs, even if the average salary remains constant (Moore 1907c: 64).

Hence, in «The Differential Law of Wages» and «The Efficiency Theory of Wages», Moore tried to test whether there was any proportionality between the salary of a worker and his efficiency, as claimed by Marshall (Moore [1911] 1967: 71-73). Assuming that efficiency is the outcome of «a balance of physical, mental, and moral qualities», as suggested in the Principles of Economics, Moore hypothesized that it would be normally distributed, as did Galton and Pearson. Moore proceeded to split the distribution into intervals, testing whether there was any correspondence with wage differences.

Moore was quoting the second edition of The Grammar of Science (Moore 1908: $11,13)$, in which correlation coefficients were still discussed in a restricted biological setting, but he was plainly conscious that the methodological principles presented therein could be applied to economics as a whole. A year before sojourning at Pearson's laboratory, Moore published his research agenda, restating Clark's programme. In «The Statistical Complement of Pure Economics» (Moore 1908), Moore discussed which statistical techniques would be of more use to economists, calling for a dynamic approach to economics in the spirit of Clark, Pareto and, most emphatically, Marshall (Moore 1908: 33). There is nothing more akin to economics than statistics, claimed Moore, if the former was to be «an engine for the discovery of concrete truth»: 
Similarly, the theory of probability as applied to the social sciences is not a body of concrete doctrine, but rather a machinery of general application in the study of mass-phenomena upon which social sciences rest. (Moore 1908: 8)

Moore explicitly assumed many distinctive Pearsonian ideas, such as the view of theories as mere data summaries, to be represented by an interpolated curve (e.g., Moore 1908: 16). In his capstone 1911 book, Laws of Wages, causation was considered a mere unit correlation $^{\mathrm{xiv}}$, reading in that light the different statistical tests conducted therein.Yet, it must be noted that, at this point in time, Moore did not go as far as Pearson regarding scientific lawfulness. The purely deductive results of the neoclassical theory were complemented, but not replaced, by the inductive findings of the statistical economist:

But suppose that the productivity theory of wages should receive inductive verification in a particular instance. In that case the confidence in the generality and the stability of the results would be far greater because of the added weight of the $a$ priori demonstration. (Moore [1911] 1967: 23)

Therefore, Moore cannot yet be pictured as a fully-fledged methodological positivist: even if he clearly meets our second methodological condition (aggregate data provided for him the proper ground for the testing of economic theory [Moore 1908: 8]), Moore did not adopt any definite position regarding utility theory and its causal import. On the other hand, as had already happened with Pareto, it is not easy to assess how statistics were to confirm our deductive results (micro or macro), apart from increasing our trust in their «stability». 
In a certain sense, Moore was accomplishing Pareto's desideratum of a statistical approximation to demand theory, though he somehow felt much closer to Marshall: a copy of The Laws of Wages was dispatched to Cambridge in 1911 in search of comments. This is key to understanding Moore's subsequent rejection of the neoclassical foundations for demand curves, which I contend may be interpreted as a result of Marshall's dismissal of his statistical approach. In fact, when Moore announced his intentions to visit him in Cambridge the following year, he received a quite unexpected answer:

I will be frank. I have had your book on Laws of Wages in a prominent place near my writing chair ever since it arrived, intending to read it when opportunity came. It has not come \& I fear it never will come. For what dips I have made into the book make me believe that it proceeds on lines which I deliberately decided not to follow many years ago [...]. (Marshall to Moore, 5/6/1912 [1013]) ${ }^{\mathrm{xv}}$

Marshall's retirement from teaching had taken place two years beforehand, so he was not lacking in time to receive Moore. It was a matter of principle: Marshall saw no point in discussing an option he had himself dismissed long before:

No important chain of events seems likely to be associated with any one cause so predominantly that a study of the concomitant variations of the two can be made as well by Mathematics, as by comparison of a curve representing those two elements with a large number of other curves representing other operative causes: the "ceteris paribus" clause - though formally adequate — seems to me impracticable. (Marshall to Moore, 5/6/1912 [1013]) 
Yet, Moore could not dispense with ceteris paribus clauses in his own statistical approach (Moore 1908: 62). Applied causal analysis in economics, as elsewhere, required statistics. Yet Marshall was questioning this very possibility:

I think each of your arguments should run somewhat in this fashion. "Here are two elements which probably have some causal connection either as father \& son, or brothers or cousins. Now if we assume that neither of them has a causal relations with any other changing element, they may be safely put into a StatisticoMathematical machine, \& the result worked out to $n$ places of decimals. But of course this is mere play. In fact they have many other causal relations: $\&$ therefore my results in reference to the real world may have errors not of .5 or .7 per cent, but of 50 or 70 per cent.” (Marshall to Edgeworth, January 1912 [1008])

He was not at all impressed by Moore's results (Marshall to Edgeworth, January 1912 [1008]), but it should be noted that it was not Moore who was to be blamed. It was Pearson himself, as Marshall had shown through their polemical exchange in The Times a year before The Law of Wages went to print. In the course of their 1910 study on the influence of parental alcoholism in children, Karl Pearson and Ethel Elderton affirmed that no statistical relation existed between alcohol abuse and wage level. But, as we previously pointed out, it had been Marshall who proposed defining efficiency as the outcome of a bundle of personal abilities, on which alcohol may obviously have very harmful effects ${ }^{\mathrm{xvi}}$. He not only contested Pearson's expertise in economics, but also the very possibility of applying statistics to disentangle economic causation: 
Economists know that nearly all their "statistics" are mere aggregates of guesses; even such relatively definite figures as those relating to exports and imports are made up largely of conjectural items. Consequently when a mathematical outsider, like professor Pearson, incessantly upbraids them for setting mere opinions against the statistical "facts" which he has culled in a hurry, they are apt to observe that if he knew more he would know that he knew less. (Marshall to the Editor, The Times, $17 / 8 / 1910[972])$

Marshall discouraged Moore from visiting him, even if his only purpose had been to know him in person (Moore to Marshall, 6/6/1912 [1014]). In Moore's response the following statement was removed: «I have spent profitable years in the study of your work» (ibid.). In my opinion, Marshall's dismissal made Moore reconsider how static and dynamic economics were to be assembled. If the ceteris paribus clauses resisted a statistical specification, how could dynamic economics on pure theory be grounded? Moore addressed this question two years later, in his Economic Cycles: their Law and Cause (Moore [1914] 1967), where demand theory was appraised as a first step towards a statistical theory of economic cycles.

The way I read it, Economic Cycles provides an unmixed positivist approach to economics, marking a juncture in Moore's career. He abandoned pure theory and opted for a plainly statistical assay. If Marshall had theorized a gradualist reconstruction of causal trends in economics by means of the ceteris paribus tool, Moore argued for directly attacking the problem of the relation of price and supply of commodities «in full concreteness» by means of multiple correlation analysis (Moore [1914] 1967: 67), which would take into account every relevant dynamic effect ${ }^{\mathrm{xvii}}$. Moore went much further: as 
long as Marshallian demand functions were statistically intractable, they can no longer be accepted as a solid grounds for the laws of demand.

According to the view of the foremost theorists, the development of the doctrines of utility and value had laid the foundations of scientific economics in exact concepts, and it would soon be possible to erect upon the new foundation a firm structure of interrelated parts which, in definitiveness and cogency, would be suggestive of the severe beauty of the mathematico-physical sciences. But this expectation has not been realized. (Moore [1914] 1967: 85)

According to Moore, economists had been mislead in their search for scientific laws by a sort of physics' envy (Moore [1914] 1967: 85; Mirowski 1990: 596-97). If utility theory cannot be accurately translated into statistical terms, it should be discarded as the basis for demand analysis, and replaced by a purely functional approach — as claimed by Mach — linking quantities and prices such as the one advanced by Cournot (Le Gall 1996). There is no need of an inquiry into the agent's market decisions, if one assumes that he follows certain routines (Schultz 1938: 65), as those pointed out by Pearson. These routines will be sufficient to generate regularities in the aggregate data. Moore certainly now fulfils the two methodological criteria defining positivism: no psychological commitments in the explanation of individual demand, but mere behavioral routines, and statistical search for the laws of demand at the aggregate level. This simply implied the rejection of neoclassical demand theory, replaced by a purely descriptive approach to data analysis in which scientific truth was statistically appraised. 
The consequences of Moore's option for this descriptivist stance are extremely noticeable in Economic cycles. In fact, having dispensed with utility theory, there was no need to expect a single law of demand, such as the universal one hypothesized by Marshall:

As we proceed we shall find that the law of demand for some commodities does indeed conform to the type of curve which has just been described, but it will be a part of the work of the next chapter to show that the doctrine of the uniformity of the demand function is an idol of the static state — of the method of ceteris paribus - which has stood in the way of the successful treatment of concrete dynamic problems. (Moore [1914] 1967: 64)

Here lies the key to understanding Moore's most controversial result: his positively sloped demand curve. Moore took the production of pig-iron as «a barometer of trade», pointing to the industrial cycle, in order to analyse whether it was somehow related to the agricultural cycle, as represented by the yield per acre of certain crops. He found a positive correlation between both cycles for lags of various intervals ${ }^{\text {xiii }}$, and then argued as follows:

Upon the assumption that all demand curves are of the negative type, it would be impossible for general prices to fall while the yield per acre of crops is decreasing. In consequence of the decrease in the yield per acre, the price of crops would ascend, the volume of commodities represented by pig-iron would decrease, and upon the hypothesis of the universality of the descending type of demand curves, the prices of commodities like pig-iron would rise. In a period of declining yield of crops, therefore, there would be a rise of prices, and in a period of increasing yield 
of crops there would be a fall of prices. But the facts are exactly the contrary. (Moore [1914] 1967: 112)

Moore tested his intuition on four different varieties of pig iron for a twenty-year interval (1870-1912), and obtained a positively sloped demand curve ${ }^{x i x}$. He blatantly concluded:

It is obviously inadmissible to assume that in a dynamic society there is one law of demand for all commodities. The dogma of the uniformity of the law of demand is an idol of the static state. (Moore [1914] 1967: 113)

The curve proved to be irresistibly attractive for many readers, shifting their attention from what Moore considered his most significant result — «the cause and law of economic cycles have been discovered», he proclaimed (Moore [1914] 1967: 116). Among the six reviews of Economic Cycles mentioned by George Stigler (Stigler 1962: 20) ${ }^{\mathrm{xx}}$, only one by Udny Yule seems to notice that Moore had abandoned utility theory, while the other five criticised his results for contradicting it. More than a decade later, Moore's most prominent disciple, Henry Schultz, made it explicit: «[t]he result is not the static law of demand in the Marshallian sense, since only one disturbing factor $[\ldots]$ is held constant.» (Schultz 1931a: 653; 1938: 82)

According to Mary Morgan, there are two alternative approaches in discussing Moore's controversial curve (Morgan 1990: 167-68). On the one hand, it may be interpreted as a matter of choosing the correct theoretical model, assuming that its correction is to be assessed from neoclassical demand theory. On the other hand, for the majority of Moore's critics the problem lies in extracting that model from the data, as we 
will see in the next section. However, as a result of my previous discussion, I tend to agree with Michel Armatte (Armatte 1995: ch. 12.5.2; cf. also Mirowski 1990) on reading Moore as tackling quite a different issue, an epistemological one. It was the very idea of scientific truth to be applied in economics that Moore put at stake with his curve. The underdetermination dilemma raised by Pareto stops making sense when every scientific law is assumed to be statistically translatable into the data, since correlation analysis provides a tool to rank its accuracy. An accomplished positivist now, as much methodologically as epistemologically, Moore was no longer a neoclassical economist. It was up to his disciple Henry Schultz to reconcile statistics with the Paretian programme.

\section{WhAT STATISTICAL DEMAND CURVES SHOWED TO HENRY SCHULTZ}

A decade after the publication of Economic Cycles, in his presidential address delivered at the meeting of the American Economic Association, Wesley Clair Mitchell vindicated Moore's statistical approach to economics over Alfred Marshall' skepticism (Mitchell 1925: 23). But it was not only Marshall. The debate on quantitative social science was at his peak in the mid 1920s, and the economists were not absent. After the foundation of the National Bureau of Economic Research (NBER) and the Social Science Research Council (SSRC), economics was making its way into the Big Sciences (Hands and Mirowski 1997). At a time when statistics was a discipline almost unknown to the profession, the more attractive quantitative analysis became, the more it was funded. However, there were many who felt that economics was being downgraded into mere political arithmetic — as the Marshallian Jacob Viner once put it — by «the mere mechanical search for mutual dependencies among data selected almost at random» (Viner 
1928: 33). The enthusiasts of correlation analysis could not pretend not to hear. Henry Schultz was one of the most prominent among them.

Schultz had been trained as an economist by Mitchell and Moore at Columbia, and was to go on to obtain a position at Chicago. Under the patronage of the SSRC, Schultz contributed to creating and directing a statistical laboratory (Hotelling 1939: 98), whose facilities met the most demanding standards of the time (Mitchell 1925: 22). The conditions were ideal to undertake Viner's challenge and «bridge the gap between factless theory and theoryless fact» (Yntema 1939: 159). In other words, to reconcile Moore's statistical approach with neoclassical demand analysis.

Having visited Pearson at the Galton Laboratory in 1919, Schultz was certainly familiar with his epistemology and how Moore, his doctoral advisor, had applied it to economics. Schultz adhered indeed to a functional approach to causation (Schultz 1927a: 706) and argued for a statistical appraisal of ceteris paribus clauses (Schultz 1925: 462; 1928a) and demand theory as a whole (Schultz 1931a: 660). However, he was also plainly explicit in admitting that general equilibrium theory «is the only type of scientific theory we have» (Schultz 1928b: 647), which is not so unpredictable a statement from a devoted reader of Pareto, such as Schultz was from the very beginning of his career (Hotelling 1939: 99; Yntema 1939: 155-56). While committing himself to the methodological prescriptions already applied by Pareto and Moore to demand theory, Schultz explored a third epistemological way of his own during the first part of his career. Schultz's adequationism may indeed be understood as a sort of compromise between their respective positions. On the one hand, Moore's descriptionism had to be softened if one wished to count on utility theory. Yet, Schultz needed to redeem it from the charge of lacking 
empirical content so that it could constitute the basis of aggregate demand analysis. This was necessary, on the other hand, since Schultz also wished to abandon Pareto's conventionalism: the truth of neoclassical demand theory was to be established once and for all, as the only one that could account for the data. Despite Pareto's warning of the possibility of having many more, statistics would simply rule out any underdetermination dilemma.

I will discuss Schultz's initial project in two steps: its enactment and its subsequent crisis. Schultz's studies realized his adequationist agenda for a brief five-year period. The debate on the theoretical significance of statistical demand curves sparked off by Elmer Working brought it to an abrupt close. Let me proceed again from the micro to the macro level. It was at the former where Schultz had to answer Moore's objections to utility theory, basically its statistical irrelevance (Moore [1914] 1967: 86). To tackle this, the obvious way for a disciple of both Pareto and Mitchell working hand in hand with quantitative psychologists — such as Louis Thurstone, who would later contribute to the establishment of the Psychometric Society - was to turn towards experimentation (Schultz 1925: 631; 1931b: 487-89). The Psychometric Laboratory at the same Social Sciences Building in Chicago hosted their attempt to obtain an experimental indifference curve in the early

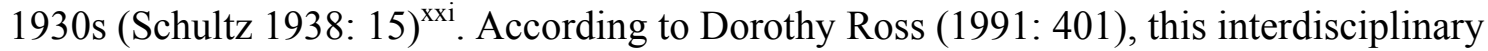
approach was typical of the SSRC scientists, and it did not imply that economics were to be somehow reduced to psychology (Schultz 1933b: 115). In fact Schultz did not proceed further along this path, as his methodological point was already made. Utility theory may be hence empirically tested, meeting the strict positivist requirements of Pareto and Moore: 
it did not refer to any psychological unobservable magnitude, and was therefore statistically testable.

Yet, Schultz acknowledged that most agents would not probably know how to answer when interviewed by the experimentalist about their preferences regarding different combinations of quantities and prices. That is, the truth of demand theory, as the positivist claimed, did not lie at the micro level: to obtain empirical demand functions, the theorist should observe how consumers behave in masses (Schultz 1931a: 649). Individual actions, even if not fully logical in a Paretian sense, give rise to collective routines of change (Schultz 1928b: 643) amenable to a statistical analysis.

Once it was established that the laws of demand were theoretically well-grounded at the micro level, the issue to address was how to contrast demand theory on aggregate data. Schultz chose to follow Pareto's suggestion (Pareto [1909] 1981: 234; Schultz 1928b: 645) on the practical impossibility of a standard predictive approach, i.e, deriving ex ante a set of equilibrium prices to verify whether it was obtained in a given market. He opted for reconstructing empirical demand curves assisted by Moore's techniques to test whether they exhibited the properties anticipated by the theory (in particular, those concerning the sign of the slope and the elasticity). Although meeting the positivist desideratum of contrasting economic theories on aggregate data by statistical means, Schultz clearly departed from Pareto's epistemological stance. For now the issue at stake was not to choose a theoretical account for a certain data set, as Pareto had intended: there was a single theory of demand to contrast, and the way to do it was to verify the correspondence between the properties of the statistical and the theoretical demand curves. Here is what Schultz's adequationism consists of. 
As Moore clearly anticipated, the most difficult problem to handle was that of fitting a dynamic sequence of price data into a single static curve, as if the market conditions remained constant during the period considered, i.e., assuming that the curve does not shift ${ }^{\mathrm{xxi}}$. Schultz initially thought that the statistical smoothing of those time series would be enough so to dispense with ceteris paribus clauses, as Moore taught (Schultz 1928b: 648) ${ }^{\mathrm{xxiii}}$. His doctoral dissertation on the demand for sugar exemplifies Schultz's opening approach: to eliminate shifts caused by changes in the general price level or by the rising popularity of sugar as a consumption good, it was enough to apply trend ratios or link relatives to the data (Schultz 1925: 502). However, Moore's techniques were not intended to deal with neoclassical demand curves, as Schultz was soon forced to acknowledge. Yet, statistics offered alternative ways to cope with shifts ${ }^{\text {xxiv }}$, such as those which Holbrook Working had already advanced. According to the elder Working, the shifting of a curve would produce a distribution of points scattered as if an error occurred in measuring the variable (Working 1925: 531). As measurement errors could be reduced by means of orthogonal regressions (Epstein 1987: 42; Schultz 1925: 581), these would produce a better fitting of the theoretical demand curve.

To sum up, in the very first stage of his career, Schultz adhered to the positivist methodology inherited from Pareto and Moore, while developing an epistemological approach of his own. Key to both was the use of statistics. It guaranteed the empirical endowment of demand theory, as much for the micro as for the macro level: since the theory was to be tested at the latter, statistics ensured that empirical demand curves could meet their theoretical counterparts, without imposing other assumptions on the data than 
those derived from the statistical technique itself. Schultz's adequationist is thereby defined.

However Schultz's initial expectations did not last long: in 1927, Elmer Working's most influential «What do Statistical Demand Show?» brought them to an end. Though this paper certainly deserves a methodological discussion on its own, I suggest reading it here as a response to his brother's claim. Elmer showed indeed that only under certain assumptions about the way the curves shifted was a statistical test feasible. For instance, if the shifts of the demand and the supply curve were correlated, the statistician would be unable to trace the latter, as its elasticity would be not remain constant from point to point. According to Working, we will have mere regression curves then, useful for predictive purposes but with no theoretical relevance whatsoever (Working 1927).

Philip Wright made a similar case about Schultz's Statistical Laws of Demand and Supply (Schultz 1928a), drawing the same conclusion: his analyses would be more of heuristic value than conclusive (Wright 1929: 214). Schultz's rejoinder to Working and Wright (Schultz 1930: 29; 1938: 73) accepted their objections unreservedly: only under certain assumptions about the way the curve shifted could the econometrician appraise them. According to Schultz, the assumptions underlying Moore's approach were not of a very different kind, as he expected the data to show certain routines of change (Schultz 1930: 36). These routines were generated by the variations of prices and quantities in the short run; those happening in the long run will be intractable by means of Moore's smoothing techniques (Schultz 1930: 37). 
Yet, taking Working's point amounted to much more than a mere restriction in scope of Schultz's approach. It implied a substantial amendment of his epistemological endeavour: «The statistical law may only be approached but never realized in inductive investigations» ${ }^{\mathrm{xxv}}$. In other words, there were no prospects in sight for a dynamic reconstruction (Schultz 1938: 84) of static demand curves. Neither were there for Schultz's adequationism: accepting that the theoretical demand curves could only be approached under certain assumptions derived from the theory itself was tantamount to accepting that the rational acceptance of demand theory will always be underdetermined by any conceivable evidence $^{\text {xxvi }}$. However, throughout the 1930s Schultz attempted to test it, now in a general equilibrium framework where each assumption may be explicitly taken into account. Unfortunately, it was only to discover that it was rationality itself which was put into question by the data (Schultz 1933c: 501). Auxiliary hypotheses were invoked to prevent this from happening (Schultz 1933c: 507-509; 1938: 599-604). Instead of a pure statistical reconstruction, he had to settle for a mere theoretically constrained approximation (Schultz 1938, pp.173).

\section{CONCLUSION}

The works by the three authors examined in this paper exemplify a certain methodological approach to demand theory which I take to be distinctively positivist, even several decades before neopositivism was introduced into economics. For the purpose of this analysis, this older brand of positivism may be understood as a reaction to the causal programme of mechanistic physics, advocating instead a phenomenalistic conception of truth in which causation was reduced to a purely functional dependence. While drawing on different sources, our three demand theoreticians converged on the exclusion of inner 
psychological causation when explaining choices. The truth of the explanans lay not in the causal mechanism it postulated, but depended instead on its statistical performance in a descriptive analysis of aggregate data.

The relationship between demand theory and data gave rise to three different epistemological approaches, of which I have discussed the collapse of two. Under the influence of Pearson, Moore simply renounced neoclassical demand theory insofar as it was statistically intractable, opting instead for a mere description of the data by means of correlation analysis. Schultz initially advocated a correspondence view of truth, in which a theoretical entity such as a demand curve was also empirically reconstructed by statistical means. When he discovered that the reconstruction was feasible only under certain theoretical assumptions which prevented a purely data based approach, the alternatives open to him were either taking sides with Moore and abandoning neoclassical demand curves or returning to Pareto's conventionalism.

Schultz opted for the latter, but unlike Pareto, he could not expect the situation to improve as a result of the advancement of statistical economics. No theoretically independent reconstruction of demand curves could be undertaken or, at least, some among the next generation of demand theorists were soon led to think so. In a controversial paper at the Journal of the American Statistical Association the young George Stigler, a former student of Schultz in Chicago, gave voice to the opinion that statistical demand curves were intrinsically limited. Taking up again the case made by Elmer Working (Stigler 1939: 47277), Stigler added new arguments to get to the same point: nothing but an approximation could be expected from statistical demand curves: 
Statistical demand curves are still remote from the demand curves of the economic theorist. In the writer's opinion, the gap between the two types of demand curve will never be completely bridged, and in any case, that rapprochement is likely to be slow. (Stigler 1939: 481)

Unlike Schultz, Stigler took this epistemological stance its his logical conclusion, making totally explicit the criteria by which the approximation will be judged:

It is noteworthy that with very few exceptions, the statistical economists have insisted that only "reasonable" results be accepted. "Reasonableness" includes many things, but it seems here to involve primarily a close approximation to a priori expectations. Each procedure has its merits, but it must be remembered that statistical demand curves are published because they do not violate our theoretical preconceptions, and therefore they give a specious authentication of these statistical products. (Stigler 1939: 481)

[S]ince the leading workers in the field of statistical demand analysis have generally been competent and frequently outstanding economic theoreticians, they have usually accepted the relevance of theoretical demand curves as criterion of their progress. (Stigler 1939: 470)

Whereas Pareto warned of the possibility of having many theoretical accounts for a given body of evidence, so that it can be only approximated but never exhausted through any of them, Stigler argued for a reversed conventionalism: a theoretical entity, such as the demand curve, could be statistically approximated in various ways but never completely reconstructed, and it corresponded to our «theoretical preconception» to evaluate their 
degree of convergence. As the arch-positivist Milton Friedman once put it, «a theory is the way we perceive "facts", and we cannot perceive "facts" without a theory» (Friedman 1953b: 34).

A positivist demand theorist in the tradition herein examined will adhere to the two methodological prescriptions discussed above. This commitment did not however entail any particular epistemological stance, and depending on that adopted, the truth of demand theory may be assessed in completely opposite directions. Yet, it must be noted that the main alternatives discussed in our paper involved either rejecting the neoclassical framework (Moore) or accepting to a certain degree its underdetermination by the data (Pareto, Schultz and Stigler). The quest for accurate predictions that distinguished the positivist tradition after Friedman may itself be reassessed from this point of view.

David Teira

UNED and Urrutia Elejalde Foundation dteira@ffsof.uned.es

\section{Acknowledgements}

Thorough comments by F. Guala, W. Hands, U. Mäki, J. Urrutia and J. Zamora are gratefully acknowledged. I also thank J. F. Álvarez, M. Armatte, M. Barbut, S. Barberá, J. Davis, J. Echeverría, J. C. García-Bermejo, J. Ruiz-Castillo and J. C. Zapatero for their suggestions. This research was funded by the grant BF2003-04372 and the Urrutia Elejalde Foundation. The usual disclaimer on intellectual responsibility applies. 
References

Álvarez, N. (1996) Introducción a la metodología de la economía, Madrid: UNED

Armatte, M. (1995) Histoire du Modèle linéaire, Unpublished Doctoral Dissertation, Paris: EHESS.

Barbut, M. (1999) 'Pareto et la statistique', in Alban Bouvier (ed.) Pareto aujourd'hui, Paris: PUF, pp. 85-109.

Bean (1931) 'Review of H. Schultz, The Meaning of Statistical Demand Curves', Journal of the American Statistical Association 26: 481-84.

Bruni, L. (2002) Vilfredo Pareto and the Birth of Modern Microeconomics, LondonN.York: Edward Elgar.

Bruni, L., and Guala, F. (2001) 'Vilfredo Pareto and the Epistemological Foundations of Choice Theory', History of Political Economy 33: 21-49.

Caldwell, B. (1994) Beyond Positivism, London-N.York: Routledge.

Clark, J.B. (1899) The Distribution of Wealth, N.York: MacMillan.

Clark, J.B. (1905) 'The Field of Economic Dynamics', Political Science Quarterly 20: 24656.

Clark, J.B. (1907) Essentials of Economic Theory as Applied to Modern Problems of Industry and Public Policy, N.York: MacMillan.

Dewey, D. (1987) 'Clark, J. B', in J. Eatwell et al. (eds.) The New Palgrave: A Dictionary of Economics, London: Macmillan, pp. 428-31.

Dorfman, J. (1941) 'The Seligman Correspondence I', Political Science Quarterly 56: 10724. 
Epstein, R. (1987) A History of Econometrics, Amsterdam: Elsevier.

Ezekiel, M. (1928) 'Statistical Analyses and the "Laws" of Price', Quarterly Journal of Economics 42: 199-227.

Fanno, M. (1916) 'Review of Economic Cycles: Their Law and Cause', Giornale degli Economisti 52: 151-54.

Fernández, A. \& D. Teira (2003) 'Henry Ludwell Moore y la introducción del positivismo estadístico en economía', in. G. Marques et al. (eds.) Objetividad, realismo y retórica, Madrid: FCE, pp. 167-198.

Hands, D. W. (2001) Reflection without rules: Economic methodology and contemporary science theory, Cambridge: Cambridge University Press.

Hands, W. \& P. Mirowski (1997) 'Harold Hotelling and the Neoclassical Dream', in R. Backhouse et al. (eds.) Economics and Methodology: Crossing the Boundaries, London: Macmillan, pp. 322-97.

Hotelling, H. (1938) 'Review of H. Schultz, The Theory and Measurement of Demand', Journal of the American Statistical Association 33: 744-47.

(1939) 'The Work of Henry Schultz', Econometrica 7: 97-103.

Ingrao, B. \& G. Israel (1990) The Invisible Hand. Economic Equilibrium in the History of Science, Cambridge (Mass.)-London: The MIT Press.

Kirman, A. (1998) 'Vilfredo Pareto', in F. Meacci (ed.) Italian Economists of the 20th Century, London: Edward Elgar.

Klein, J. (1997) Statistical Visions in Time: a History of Time Series Analysis, 1662-1938, N.York: Cambridge U.P.

Le Gall, P. (1996) 'Une énigme de l'histoire de l'économétrie: L'étrange demande de lingots de fonte de Henry Moore (1914)', Revue d'Economie Politique 106: 293-318. 
Lehfeldt, R.A. (1915) 'Review of Economic Cycles: Their Law and Cause', Economic Journal 15: 409-11.

Magge, J.D. (1915) 'Review of Economic Cycles: Their Law and Cause', Journal of Political Economy 23: 514-17.

Marchionatti, R. \& E. Gambino (1997) 'Pareto and Political Economy as a Science', Journal of Political Economy 105: 1322-48.

Mirowski, P. (1990) 'Problems in the paternity of econometrics: Henry Ludwell Moore', History of Political Economy 22: 587-609.

Mirowski, P. (2002), Machine Dreams. Economics Becomes a Cyborg Science, Cambridge University Press, Cambridge, 2002.

Mitchell, W.C. (1925) 'Quantitative Analysis in Economic Theory', American Economic Review 15: 1-12.

Mongin, P. (1988) 'Problèmes de Duhem en théorie de l'utilité espérée', Fundamenta Scientiae 9: 289-317.

Moore, H.L. (1895) 'Von Thünen's Theory of Natural Wages', Quarterly Journal of Economics 9: 291-304, 88-408.

Moore, H.L. (1907a) 'The Differential Law of Wages', Journal of the Royal Statistical Society 70: 638-51.

Moore, H.L. (1907b) 'The Efficiency Theory of Wages', Economic Journal 17: 571-79.

Moore, H.L. (1907c) 'The Variability of Wages', Political Science Quarterly 22: 61-73.

Moore, H.L. (1908) 'The Statistical Complement of Pure Economics', Quarterly Journal of Economics 23: 1-33.

Moore, H.L. ([1911] 1967) Laws of Wages: an Essay in Statistical Economics, N.York: Kelley. 
Moore, H.L. ([1914] 1967) Economic Cycles: their Law and Cause, N.York: Kelley.

Morgan, M. (1990) The History of Econometric Ideas, Cambridge: Cambridge University Press.

Pareto, V. ([1895] 1982) 'La legge della domanda', in Idem, Ecrits d'économie politique pure, Geneva: Droz, pp. 295-305.

Pareto, V. ([1900] 1982) 'Sunto di alcuni capitoli di un nuovo tratatto di economi pura del prof. Pareto' in Idem, Ecrits d'économie politique pure, Geneva: Droz, pp. 385-424.

Pareto, V. ([1907-8] 1982) 'L'interpolazione per la ricerca delle legi economiche' in Idem, Ecrits d'économie politique pure, Geneva: Droz, pp. 575-626.

Pareto, V. ([1908] 1982) ‘Economia sperimentale', in Idem, Ecrits d'économie politique pure, Geneva: Droz, pp. 626-43.

Pareto, V. ([1909] 1981) Manuel d'économie politique, Ginebra: Droz.

Pareto, V. ([1911a] 1966) Cours d'Économie Politique, Geneva: Droz.

Pareto, V. ([1911b] 1966) 'Economie mathématique', in Idem, Statistique et Économie mathématique, Geneva: Droz, pp. 319-68.

Pearson, K. (1900) The Grammar of Science, $2^{\text {nd }}$ edition, London: Adam and Charles Black.

Pearson, K. (1911) The Grammar of Science, $3^{\text {rd }}$ edition, London: Adam and Charles Black.

Persons, W.M. (1915) 'Review of Economic Cycles: Their Law and Cause', American Economic Review 5: 645-48.

Poincare, H. ([1902] 1968) La science et l'hypothèse, Paris: Flammarion. 
Porter, T. (2004) Karl Pearson. The Scientific Life in a Statistical Age, Princeton: Princeton University Press.

Qin, D. (1989) 'Formalization of Identification Theory', Oxford Economic Papers 41: 7393.

Rosenberg, A. (1995) Philosophy of Social Science, Boulder-Oxford: Westview Press.

Ross, D. (1991) The Origins of American Social Science, Cambridge: Cambridge University Press.

Sawyer, K.R., C. Beed \& H. Sankey (1997) 'Underdetermination in Economics. The Duhem-Quine Thesis', Economics and Philosophy 13: 1-23.

Schultz, H. (1925) 'The Statistical Law of Demand as Illustrated by the Demand for Sugar', Journal of Political Economy 33,: 481-504 y 77-637.

Schultz, H. (1927a) 'Mathematical Economics and the Quantitative Method', Journal of Political Economy 35: 702-06.

Schultz, H. (1927b) 'Theoretical Considerations Relating to Supply', Journal of Political Economy 35: 437-64.

Schultz, H. (1928a) Statistical Laws of Demand and Supply with Special Application to Sugar, Chicago: Chicago University Press.

Schultz, H. (1928b) ‘Rational Economics', American Economic Review 18: 643-648.

Schultz, H. (1930) Der Sinn der Statistischen Nagfragekurven, Bonn: Veröffentlichengen der Frankfurter Gesellschaft für Konjunkturforschung.

Schultz, H. (1931a) 'Moore's Contribution to the Statistical Law of Demand', in Stuart A. Rice (ed.) Methods in Social Science, Chicago: University of Chicago Press, pp. 644-61. 
Schultz, H. (1931b) 'Review of G. C. Evans, Mathematical Introduction to Economics', Journal of the American Statistical Association 26: 484-91.

Schultz, H. (1931c) 'The Italian School of Mathematical Economics', Journal of Political Economy 39: 76-85.

Schultz, H. (1933a) 'A Comparison of Elasticities of Demand Obtained by Different Methods', Econometrica 1: 274-308.

Schultz, H. (1933b) 'Frisch on the Measurement of Utility', Journal of Political Economy 41: 95-116

Schultz, H. (1933c) 'Interrelations of Demand', Journal of Political Economy 41: 468-513.

Schultz, H. (1938) The Theory and Measurement of Demand, Chicago: Chicago U.P.

Stigler, G. (1939) 'The Limitations of Statistical Demand Curves', Journal of the American Statistical Association 34: 469-81.

Stigler, G. (1962) 'Henry L. Moore and Statistical Economics', Econometrica 30: 1-21.

Stigler, S. (1999) 'Karl Pearson and the Cambridge Economists', in S. Stigler, Statistics on the Table, Cambridge (Mass.): Harvard U.P., pp. 13-50.

Viner, J. (1928); 'The Present Status and Future Prospects of Quantitative Economics', American Economic Review 18: 80-86.

Whitaker, J. (ed.) (1996) The Correspondence of Alfred Marshall, Economist, Cambridge: Cambridge University Press.

Working, E. (1927) 'What do Statistical Demand Curves Show?', , Quarterly Journal of Economics 41: 212-35.

Working, H. (1925) 'The Statistical Determination of Demand Curves', Quarterly Journal of Economics 39: 503-43. 
Wright, P. (1915) 'Review of H. L. Moore, Economic Cycles: Their Law and Cause', Quarterly Journal of Economics 39: 631-41.

Wright, P.H. (1929) 'Review of H. Schultz, Statistical Laws of Demand and Supply', Journal of the American Statistical Association 24: 207-15.

Yntema, T. (1939) 'Henry Schultz: his Contributions to Economics and Statistics', Journal of Political Economy 47: 153-62.

Yule, G. U. (1915) 'Review of H. L. Moore, Economic Cycles: Their Law and Cause', Journal of the Royal Statistical Society 78: 302-305. 
${ }^{i}$ E.g., the now canonical Caldwell 1994; for a more recent discussion see Hands 2001.

${ }^{i i}$ E.g., Roger Backhouse: «To understand Samuelson and Friedman [their positivist views, DT], one needs to consider Henry Schultz and debates in the 1920s and 1930s over demand theory.» Cf. the debate on «Mainstream economics and logical positivism» at the Hes mailing list archive: http://www.eh.net/lists/archives/hes/oct-1998/0001.php

iii Cf. e.g., Ingrao and Israel 1990: 113-121.

${ }^{\text {iv }}$ I will henceforth briefly address Paretian choice theory drawing on Bruni and Guala's account. I will make my case commenting mainly on Pareto's Manuel d'économie politique (Pareto [1909] 1981), where Poincaré's influence is most evident. Kirman 1998 comments on the turn in Pareto's thought by the time La science et l'hypothèse first appeared. I quote the Manuel by the French critical edition, indicating chapter and section.

${ }^{\mathrm{v}} \mathrm{I}$ have discussed the relevance of this trend in positivism to the patterns of explanation in economics in Fernandez \& Teira 2003.

${ }^{\text {vi }}$ Cf. Poincaré [1902] 1968, chs. 6, 9 and 11.

vii «Moreover, the same facts may be explained by an infinity of theories, all equally true, because they all reproduce the facts to be explained. It is in this sense that Poincare could say that from the very fact that a phenomenon allows one mechanical explanation, it allows an infinity of them.» (Pareto [1909] 1981: 44 ). Pareto also cited Poincaré's Les méthodes nouvelles de la mécanique céleste (Pareto [1909] 1981: 15).

viii Pareto [1909] 1981: 543-4. Cf. Poincaré [1902] 1968: 147.

${ }^{\text {ix }}$ Notice that it may be justified in various other ways, as Paul Samuelson did, for instance: see Bruni and Guala 2001, where his approach is compared to Pareto's. 
${ }^{\mathrm{x}}$ Pareto [1909] 1981: 173. Cf. also Pareto [1911b] 1966: 319.

${ }^{x i}$ Though Pearson also entertained openly idealistic positions now discussed in depth by Porter 2004.

xii The book was already completed by 1895 , a year before Moore presented his dissertation: see Clark's letters to Seligman dated 17 /10/1890 (Dorfman 1941: 111-112), 30/5/1891 (pp. 113-114) and 6/4/1892 (pp. 114-115).

${ }^{x i i i}$ By the time Moore published the series of three papers containing his statistical results on wages, Clark stated that a dynamic approach to economics was yet to be attained (Clark 1907: v). Yet Laws of wages was dedicated to him.

xiv «If the relation between the two is one of cause and effect, that is to say, if the wages of unskilled labourers are determined by the means of subsistence, then the degree of association must approach unity» (Moore [1911] 1967: 30). Moore cited Pearson's Grammar immediately in support of his thesis: cf. Moore [1911] 1967: 32 and also Moore [1911] 1967: 112.

${ }^{\mathrm{xv}}$ The letters are cited by their number in the Whitaker edition (Whitaker 1996).

${ }^{\mathrm{xvi}}$ Marshall did not understand that Pearson and Elderton were in search for an index of their general ability, while the correlation between efficiency and wages was irrelevant for them. (Stigler 1999: 26)

${ }^{\text {xvii }}$ On Moore's contribution to time series analysis cf. Klein 1997: 249-256.

${ }^{\text {xviii }}$ More precisely, Moore correlated the deviations of the cycles from their respective secular trends, once their time series have been both smoothed by means of moving averages.

${ }^{\text {xix }}$ Moore's results are discussed in Armatte 1995: ch. 12.1.5 and Álvarez 1996: 117-18. Le Gall 1996 presents his 1914 book as a prelude to subsequent works. 
${ }^{x x}$ Cf Lehfeldt 1915, Magee 1915, Persons 1915, Wright 1915, Yule 1915 and Fanno 1916.

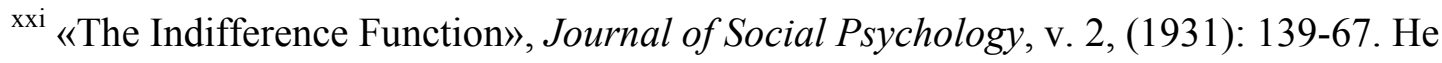
was already quoting this paper in Schultz 1931c: $78 \mathrm{n}$. Two other papers by Thurstone were quoted in Schultz 1933b, p. 116: «A Mental Unit of Measurement», Psychological Review, v. 34/6, (1927): 415-23 y «Psychophysical Analysis», American Journal of Psychology, v. 38 (1927): 368-89.

${ }^{x x i i}$ As Mordechai Ezekiel put it: «[A]ll that need to be assumed is that the position of the curve is changing in such a way that the change can be measured and eliminated, so that then at least the shape of the curve, and its position at a specified time, or under specified conditions, may be inferred from the corrected data» (Ezekiel 1928: 212).

xxiii This is, in my opinion, the proper place to discuss Percy Bridgman's influence on Schultz — against Mirowski 2002: 192: an operational definition of demand based on its measurement procedures cannot be conceived of for him if the action of time is excluded. The Logic of Modern Physics appeared in 1927, and it is already quoted in Schultz 1928b: 647-48 —and later: see, for instance, Schultz 1930: 17; Schultz 1938: 10-11

${ }^{\text {xxiv }}$ Another instance of Schultz's absolute trust in the power of statistics: Having to account for the different elasticities of demand that could be obtained depending on whether price or quantity was taken as the independent variable in the regression curve, he opted for a statistical rule and chose the variable that enhanced the regression's performance in the Pearsonian $\chi^{2}$ test (Epstein 1987: 20).

${ }^{\mathrm{xxv}}$ «[D]ie neo-klassischen Nachfrage- und Angebotskurven können aus der Statistik der Preise und Mengen nur abgeleitet werden, wenn wir den Einfluß der "störenden Faktoren" zu eliminieren wissen (...) Doch ist es unmöglich, in irgendeiner statistischen Untersuchung 
Korrekturen für alle störenden Faktoren zu finden und anzuwenden. Aus diesem Grunde kann man sich den theoretischen Kurven in induktiven Untersuchungen nur annähern, ohne sie je ganz zu verwirklichen.» (Schultz 1930: 37-38) This is an excerpt from the German published translation of an English text titled The meaning of Statistical Demand Curves, which Schultz circulated in photostatic copy about 1930. It was reviewed in Bean 1931. The last assertion comes from Moore (Schultz 1925: 630). Schultz often returned to it (e.g., Schultz 1933a: 276).

${ }^{x x v i}$ The relevance of the Duhem-Quine thesis for economics is assessed in Mongin 1988b, esp. p. 301. A broader treatment in Sawyer, Beed and Sankey 1997. On its particular consequences for econometrics, cf. Morgan 1990, chap. 6 and Qin 1989: 73-78. 